\title{
Peculiar Photoinduced Electron Transfer in Porphyrin-Fullerene Akamptisomers
}

\author{
A. J. Stasyuk, ${ }^{* a}$ O. A. Stasyuk, ${ }^{a, b}$ M. Solà*a and A. A. Voityuk*a,c
}

a. Institut de Química Computacional and Departament de Química, Universitat de Girona, C/ Maria Aurèlia Capmany 69, 17003 Girona, Spain.

b. Institute of Organic Chemistry and Biochemistry, Academy of Sciences of the Czech Republic, Flemingovo nám. 2, 16610 Prague, Czech Republic.

c. Institució Catalana de Recerca i Estudis Avancats (ICREA), 08010 Barcelona, Spain.

\begin{abstract}
Porphyrin-fullerene dyads are promising candidates for organic photovoltaic devices. Electron transfer (ET) properties of the molecular devices depend significantly on the mutual position of the donor and acceptor. Recently, a new type of molecular isomerism (akamptisomerism) has been discovered. In the present study, we explore how photoinduced ET can be modulated by passing from one akamptisomer to another. To this aim, four akamptisomers of quinoxalinoporphyrin-[60]fullerene complex are selected for the computational study. The most striking finding is that, depending on the isomer, the porphyrin unit in the dyad can act as either electron donor or electron acceptor. Thus, the stereoisomeric diversity allows one to change the direction of ET between the porphyrin and fullerene moieties. To understand the effect of akamptisomerism on the photoinduced ET processes a detailed analysis of initial and final states involved in the ET is performed. The computed rate for charge separation is estimated to be in the region of 1-10 $\mathrm{ns}^{-1}$. The formation of a long-living quinoxalinoporphyrin anion-radical species is predicted.
\end{abstract}

\section{Introduction}

A lot of attention is being paid to artificial photosynthesis in natural and life sciences. ${ }^{1-4}$ Design and preparation of synthetic model compounds mimicking natural light-harvesting systems is a primary challenge. ${ }^{5-10}$ Ideally, upon photoexcitation, a system of interest should give rise to a long-lived charge-separated (CS) state with a high quantum yield. ${ }^{11-15}$ Another important feature is the dissociation of the radical ion pair which prevents its recombination. Among a vast number of chromophores that have been used as the molecular components in artificial photosynthetic systems, a family of porphyrinoids is of special interest. Porphyrins exhibit rigid and rather planar structures, high light absorption in $2.6-3.2 \mathrm{eV}$ region ( $\pi-\pi^{*}$ transitions), and electron donor properties. ${ }^{16-20}$ Due to their low reduction potential, strong electron withdrawing power, high electron delocalization ability, and small reorganization energy, fullerenes are widely employed as electron acceptor in artificial photosynthetic systems. ${ }^{21-28}$ Electronic communication between donor and acceptor is another important feature which strongly depends on spatial orientation of donor and acceptor as well as on electronic properties of a molecular bridge connecting the sites..$^{29-31}$

For instance, electron transfer in covalently linked porphyrin-fullerene $\left(\mathrm{P}-\mathrm{C}_{60}\right)$ complexes is controlled by junction type of porphyrin (meso- and $\beta$ - positions). ${ }^{32,33}$ Also, spectroscopic measurements and molecular modeling showed the importance of conjugation between donor and acceptor moieties in $\beta$-alkynyl-linked fullereneporphyrin dyads, which represent a new class of $\mathrm{P}-\mathrm{C}_{60}$ systems, where the butadienyl bridge affords $\pi$-electron conjugation of porphyrin and $\mathrm{C}_{60} .{ }^{34}$ In 1994, Brothers and co-workers reported a new type of boron containing porphyrin derivatives ${ }^{35}$ with unusual coordination of boron atoms. In the molecule, the FB-O-BF fragment is threaded through the center of porphyrin and located in the porphyrin cavity in an asymmetric fashion - one of boron atoms lies in the macrocycle plane but the other one is out of it. Because of that, the boron porphyrins 
provide a new convenient platform to connect chemical fragments to the macrocyclic center (in addition to routinely used meso- and $\beta$ - positions in porphyrins). ${ }^{36-38}$

Recently, Canfield et al. have discovered a new type of isomerism called akamptisomerism. ${ }^{39}$ New descriptors parvo and amplo (from Latin "small" and "large") have been introduced to describe the corresponding isomers. Four akamptisomers of FB-O-BF-quinoxalinoporphyrin were described. The descriptors characterize the location of $\mathrm{BF}$ subunits with respect to the porphyrin pseudo-plane. The isomers undergo thermal interconversion, akamptisomerization, over a barrier of $c a .25 \mathrm{kcal} / \mathrm{mol}$. On the basis of DFT calculations, a reaction mechanism associated with the bond-angle inversion within the B-O-B fragment has been suggested.

As already noted, $\mathrm{P}-\mathrm{C}_{60}$ complexes are very promising models of artificial light-harvesting systems. In a recent paper, some of us have reported that several stereoisomers of an Ir based metal-fullerene hybrids exhibit clearly different electron transfer (ET) properties upon photoexcitation. ${ }^{40}$ In the present study, we consider the effect of akamptisomerism on photoinduced ET in the alkynyl-linked (B-O-B)-quinoxalinoporphyrin-[60]fullerene complexes. We reveal that even the direction of ET can change by passing from one akamptisomer to another. It means that the excited-state redox potentials of the porphyrin and fullerene moieties depend essentially on the isomer. A detailed analysis of locally excited and charge-separated states of the complexes is performed to explore the nature of the initial and final ET states. Finally, let us briefly mention that the compounds proposed in this work could be synthesized directly from FB-O-BF-quinoxalinoporphyrin by the displacement of fluoride from boron with Li derivatives of 1-butadiynl-2-methyl-[60]fullerene ${ }^{41,42}$ at mild conditions, by analogy with similar reactions for BODIPY. ${ }^{43,44}$

\section{Results}

\section{Structure and relative stability of the akamptisomers.}

As already noted, the boron atoms being the $\mathrm{R}$ - and $\mathrm{S}$ centers in the complexes enable the existence of akamptisomers. ${ }^{39}$ The eight possible stereoisomers can be grouped in four pairs of enantiomers with indistinguishable physical properties (except for their interaction with polarized light). Thus, we will consider only 4 stereoisomers (one from each pair). 

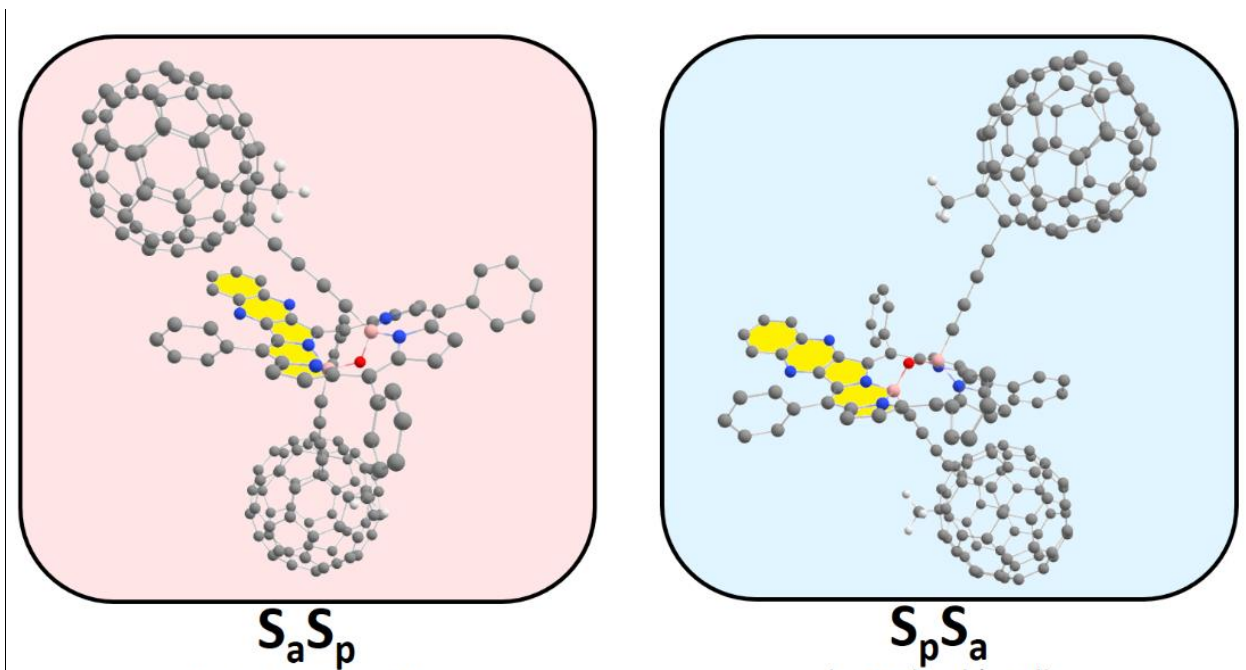

$(0.00 \mathrm{kcal} / \mathrm{mol})$

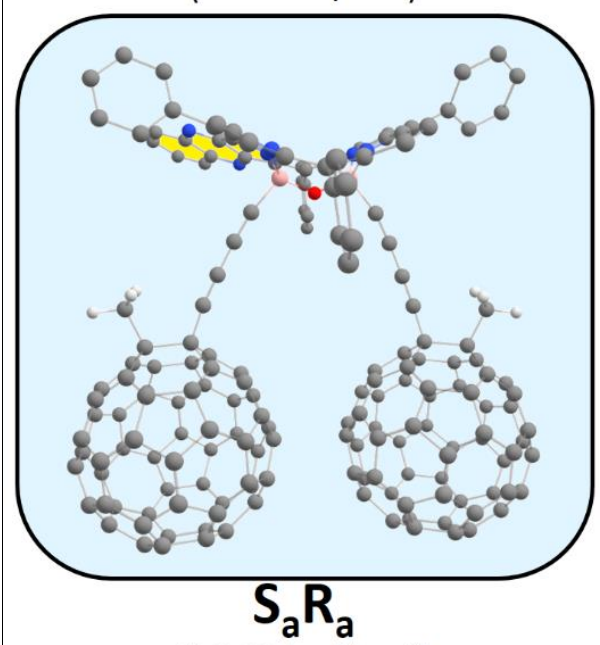

(16.29 kcal/mol)

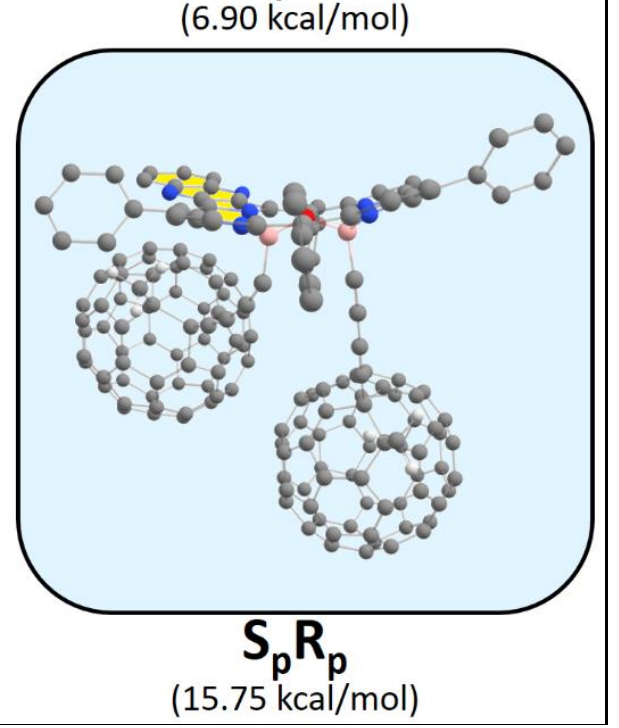

Figure 1. Structure and relative energies of transoid (top) and cisoid (bottom) akamptisomers of the alkynyl-linked $\mathrm{B}-\mathrm{O}-\mathrm{B}$-quinoxalinoporphyrin-[60]fullerene complex. Atoms $\mathrm{B}$ in peach, $\mathrm{N}$ in blue, $\mathrm{O}$ in red, and $\mathrm{C}$ in grey. The quinoxaline fragment is shown in yellow. $\mathrm{H}$ atoms are omitted for clarity. $\mathrm{R}$ and $\mathrm{S}$ refer to absolute configuration of boron atoms, the $\mathrm{p}$ (parvo) and a (amplo) indexes refer to the in- and out-of-plane boron atoms.

DFT calculations at BLYP-D3(BJ)/def2-SVP level of theory were carried out to gain insight into the structure and relative stability of the isomers in the ground state (GS). Stable structures were predicted for four complexes $S_{a} S_{p}$, $S_{p} S_{a}, S_{a} R_{a}$, and $S_{p} R_{p}$ (Figure 1 and Figure $S 1, S I$ ). Several significant differences compared to previously reported difluoro derivatives ${ }^{39}$ of quinoxalinoporphyrin should be noted. First, in contrast to difluoro structures, where only one cisoid isomer was identified, we succeeded to find the minima on the potential energy surface (PES) for both cisoid akamptisomers containing fullerene fragments. Their relative energy ( 16.3 and $15.8 \mathrm{kcal} / \mathrm{mol}$, Figure 1 ) is mainly determined by weaker non-bonded interaction of the fragments. The interaction of $C_{60}$ moiety with the quinoxaline fragment lowers the relative energy of the $S_{p} R_{p}$ akamptisomer. Second, the interaction of $C_{60}$ and porphyrin stabilizes $S_{a} S_{p}$ compared to $S_{p} S_{a}$ by $6.9 \mathrm{kcal} / \mathrm{mol}$. By contrast, the corresponding difluoro derivatives have the same energy. ${ }^{39}$ 


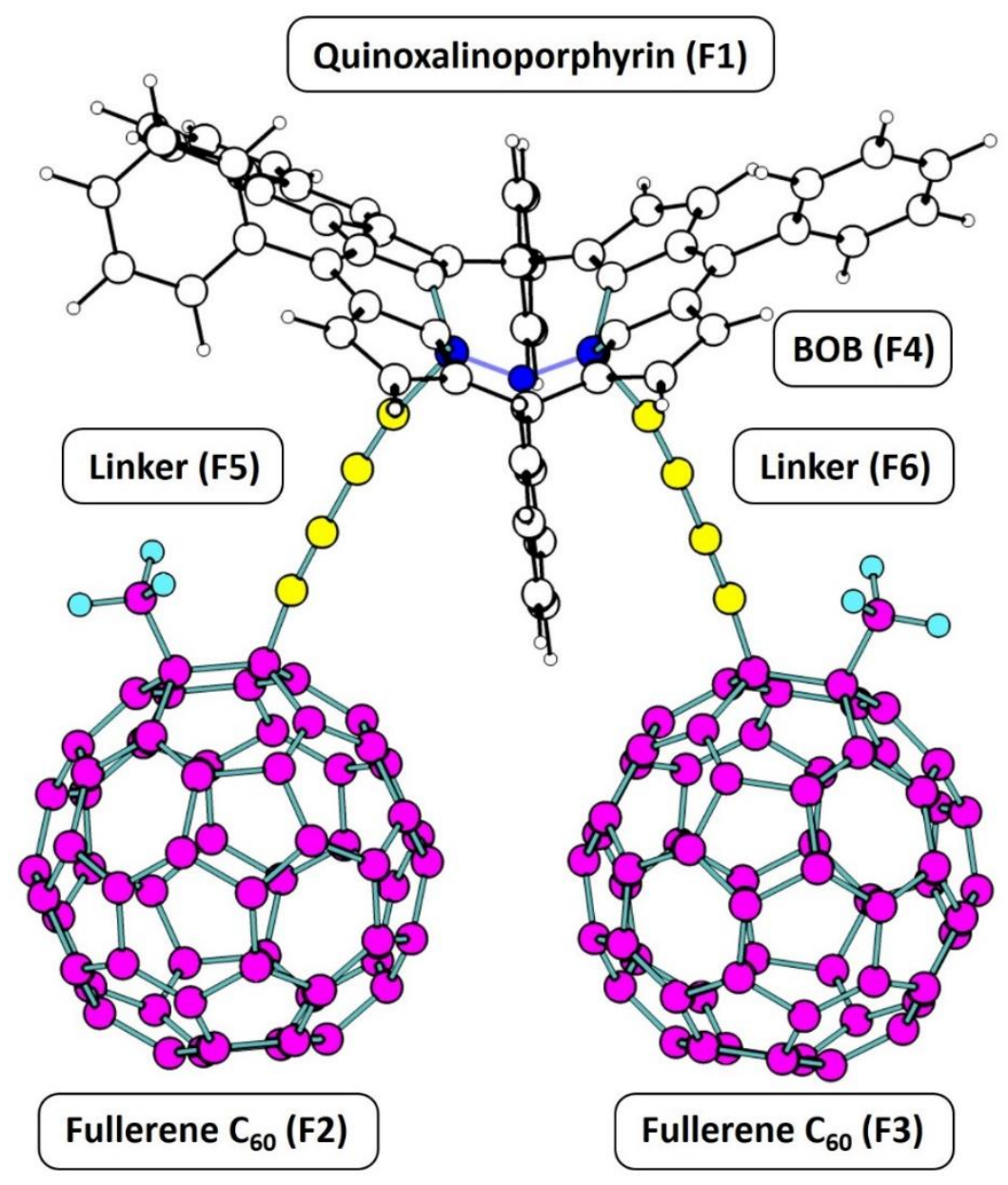

Figure 2. Fragments in $\mathrm{S}_{a} \mathrm{R}_{\mathrm{a}}$ akamptisomer: quinoxalinoporphyrin (F1) in white, fullerenes (F2 and F3) in magenta, $\mathrm{B}-\mathrm{O}-\mathrm{B}$ unit (F4) in blue and linkers ( $\mathrm{F} 5$ and $\mathrm{F} 6$ ) in yellow.

To understand the lower energy of $S_{p} R_{p}$ and $S_{a} S_{p}$ compared to $S_{a} R_{a}$ and $S_{p} S_{a}$, QTAIM calculations ${ }^{45}$ were performed. In the transoid $S_{a} S_{p}$ isomer, the strongest interactions are found between $C_{60}$ and quinoxaline and between $C_{60}$ and meso-phenyl (see Figure $\mathrm{S} 2, \mathrm{SI}$ ). At the same time in the $\mathrm{S}_{\mathrm{p}} \mathrm{S}_{\mathrm{a}}$ isomer, one fullerene (lying below quinoxaline in Figure 1) is not involved in non-covalent interactions, while another fullerene fragment demonstrates notable interaction with the meso-phenyl ring. In order to estimate the role of these interactions more directly, we calculated two model structures obtained from $\mathrm{S}_{\mathrm{a}} \mathrm{S}_{\mathrm{p}}$ and $\mathrm{S}_{\mathrm{p}} \mathrm{S}_{\mathrm{a}}$ by substituting the fullerene fragments by $\mathrm{H}$ atoms. Although the $S_{a} S_{p}$ complex is more stable than $S_{p} S_{a}$ by $6.90 \mathrm{kcal} / \mathrm{mol}$, the opposite is found for the model structures $\left(\mathrm{S}_{\mathrm{a}} \mathrm{S}_{\mathrm{p}}\right.$ is less stable than $\mathrm{S}_{\mathrm{p}} \mathrm{S}_{\mathrm{a}}$ by $2.24 \mathrm{kcal} / \mathrm{mol}$ ). Thus the observed change in stability (about $9 \mathrm{kcal} / \mathrm{mol}$ ) appears to be due to interaction of fullerenes with other fragments of the complex (see Table S2, SI for more details). The QTAIM analysis of cisoid $\mathrm{S}_{a} R_{a}$ and $S_{p} R_{p}$ akamptisomers shows that only the $C_{60} \cdots C_{60}$ interaction is significant in $S_{a} R_{a}$ whereas for $S_{p} R_{p}$ also other interactions of fullerenes with neighboring groups are identified. We note that by cutting fullerene fragments, the $S_{a} R_{a}$ isomer becomes more stable than $S_{p} R_{p}$ by $17.04 \mathrm{kcal} / \mathrm{mol}$ (Table S2, SI). Thus, fullerene-fullerene and fullerene-porphyrin interactions have a crucial impact on the relative stability of the isomers. Molecular graph with main critical points and the corresponding bonding critical point characteristics are given in Figure S2, Table S1, SI.

\section{Types of low lying excited states in akamptisomers.}

Usually, a two-fragment model is used to describe excited states in donor-acceptor complexes. In the isomers under study, however, several molecular fragments are involved in photoinduced ET. Thus, to describe the nature of excited states, we divided each system into 6 fragments: quinoxalinoporphyrin moiety (F1), two fullerenes (F2 
and $\mathrm{F} 3$ ), the $\mathrm{B}-\mathrm{O}-\mathrm{B}$ unit (F4) and two diyne bridges (F5 and $\mathrm{F} 6$ ) attached to $\mathrm{F} 2$ and $\mathrm{F} 3$, respectively. The fragmentation scheme is shown in Figure 2. Exciton delocalization and charge transfer contributions were analyzed for the 80 lowest excited states of each isomer. Three types of excited states are considered: locally excited states (LE) with the exciton mostly localized on a single fragment; CT states where the electron density is transferred between two or several fragments; and mixed states with significant contributions of LE and CT.

Excited state calculations were performed at the TDA-CAM-B3LYP/def2-SVP level. In the gas phase, the vertical excitation energy of the 80 states ranges from 2.03 to $3.85 \mathrm{eV}$ (Table 1). In all isomers, the lowest excited states are LE on porphyrin. LE states of fullerenes lie by $0.14-0.31 \mathrm{eV}$ higher in energy. As expected, most intense absorption is associated with electronic transitions in porphyrin. Depending on the isomer, their oscillator strength varies from 0.58 to 1.11 . The first CT states are found at $2.9-3.2 \mathrm{eV}$. Remarkably, the nature of the CT states is different in the transoid and cisoid isomers. For transoid isomers, the lowest CT state (CT1) corresponds to electron transfer from porphyrin to fullerene as usually observed. Depending on isomer, this state can be well described as a HOMO-LUMO+1 or HOMO-LUMO transitions. Another type of CT (CT2) is related to electron transfer from the linker to porphyrin and lies by $0.1 \mathrm{eV}$ higher in energy. The amount of charge transferred (denoted as CS in Table 1) from linker to porphyrin varies from 0.32 to $0.46 \mathrm{e}$, depending on isomer. CT states associated with ET from fullerene to porphyrin are higher in energy ( $3.62 \mathrm{eV}$ for $\mathrm{S}_{\mathrm{a}} \mathrm{S}_{\mathrm{p}}$ and $3.69 \mathrm{eV}$ for $\mathrm{S}_{\mathrm{p}} \mathrm{S}_{\mathrm{a}}$ ). In the cisoid isomers, the lowest CT states correspond to an electron transfer from the linker to porphyrin. Two other types of $\mathrm{CT}$, fullerene to porphyrin (at $3.3 \mathrm{eV}$ ) and porphyrin to fullerene (3.6 and $3.2 \mathrm{eV}$ ) were identified. Note that the excitation energy for the transition corresponding to the charge separation from fullerene to porphyrin in $S_{a} R_{a}$ and $S_{p} R_{p}$ is smaller than in $S_{a} S_{p}$ and $S_{p} S_{a}$. Finally, $C T$ states corresponding to charge separation between fullerenes are found at 3.5 and $3.4 \mathrm{eV}$ in $\mathrm{S}_{\mathrm{a}} \mathrm{S}_{\mathrm{p}}$ and $\mathrm{S}_{\mathrm{p}} \mathrm{S}_{\mathrm{a}}$ isomers respectively. In transoids, however, such CT states lie at higher energies and are not found among the calculated states.

Table 1. Singlet excitation energies ( $\left.E_{x}, e V\right)$, major orbital contributions (HOMO(H)-LUMO(L)) and their weights $(W)$, oscillator strength (f), charge separation (CS, e) and charge transfer (CT, e) quantities and the extent of exciton localization $(\chi)$ of LE states.

\begin{tabular}{|c|c|c|c|c|}
\hline & \multicolumn{4}{|c|}{ Akamptisomers } \\
\hline & \multicolumn{2}{|c|}{ Transoid } & \multicolumn{2}{|c|}{ Cisoid } \\
\hline & $\mathrm{S}_{\mathrm{a}} \mathrm{S}_{\mathrm{p}}$ & $S_{p} S_{a}$ & $\mathrm{~S}_{\mathrm{a}} \mathrm{R}_{\mathrm{a}}$ & $S_{p} R_{p}$ \\
\hline & \multicolumn{4}{|c|}{ LE1 (Porphyrin) } \\
\hline$E_{x}, e V$ & 2.034 & 2.135 & 2.143 & 2.093 \\
\hline Transition (W) & $\mathrm{H}-\mathrm{L}+4(0.43)$ & $H-1-L+3(0.35)$ & $H-1-L(0.46)$ & $H-L(0.39)$ \\
\hline$f$ & 0.024 & 0.006 & 0.025 & 0.065 \\
\hline \multirow[t]{2}{*}{$x$} & 0.956 & 0.965 & 0.970 & 0.947 \\
\hline & \multicolumn{4}{|c|}{ LE2 (Fullerene) } \\
\hline$E_{x}, e V$ & 2.339 & 2.349 & 2.279 & 2.306 \\
\hline Transition (W) & $\mathrm{H}-3-\mathrm{L}(0.87)$ & $\mathrm{H}-3-\mathrm{L}(0.90)$ & $\mathrm{H}-\mathrm{L}+1(0.63)$ & $H-1-L+1(0.50)$ \\
\hline$f$ & 0.006 & 0.006 & 0.014 & 0.007 \\
\hline$\chi$ & 0.968 & 0.975 & $0.573 / 0.362$ & 0.947 \\
\hline \multirow[t]{2}{*}{ Pertinent fragments } & F3 & $\mathrm{F} 2$ & F2/F3 & F2 \\
\hline & \multicolumn{4}{|c|}{ Most absorbtive transition (Porphyrin) } \\
\hline$E_{x}, e V$ & 3.055 & 3.282 & 3.346 & 3.157 \\
\hline Transition (W) & $\mathrm{H}-\mathrm{L}+2(0.19)$ & $H-1-L+6(0.21)$ & $\mathrm{H}-1-\mathrm{L}+4(0.35)$ & $\mathrm{H}-2-\mathrm{L}+4(0.20)$ \\
\hline$f$ & 0.581 & 1.079 & 1.113 & 0.911 \\
\hline \multirow[t]{2}{*}{$x$} & 0.532 & 0.665 & 0.889 & 0.646 \\
\hline & \multicolumn{4}{|c|}{ CT1 (Porphyrin $\rightarrow$ Fullerene) } \\
\hline$E_{x}, e V$ & 3.148 & 3.135 & 3.584 & 3.237 \\
\hline
\end{tabular}




\begin{tabular}{|c|c|c|c|c|}
\hline Transition (W) & $H-L+1(0.94)$ & $H-L(0.91)$ & $\mathrm{H}-1-\mathrm{L}+1(0.95)$ & $H-L+1(0.65)$ \\
\hline$f$ & $<0.001$ & 0.029 & $<0.001$ & 0.067 \\
\hline $\mathrm{CS} / \mathrm{CT}$ & $0.991 / 0.997$ & $0.945 / 0.980$ & $0.963 / 0.997$ & $0.663 / 0.784$ \\
\hline \multirow[t]{2}{*}{ Pertinent fragments } & $\mathrm{F} 1 \rightarrow \mathrm{F} 2$ & $\mathrm{~F} 1 \rightarrow \mathrm{F} 2$ & $\mathrm{~F} 1 \rightarrow \mathrm{F} 2 / \mathrm{F} 3$ & $\mathrm{~F} 1 \rightarrow \mathrm{F} 2$ \\
\hline & \multicolumn{4}{|c|}{ CT2 (Linker $\rightarrow$ Porphyrin) } \\
\hline$E_{x}, e V$ & 3.270 & 3.181 & 3.165 & 2.931 \\
\hline Transition (W) & $\mathrm{H}-\mathrm{L}+4(0.13)$ & $H-1-L+6(0.13)$ & $\mathrm{H}-15-\mathrm{L}(0.44)$ & $\mathrm{H}-10-\mathrm{L}(0.66)$ \\
\hline$f$ & 0.124 & 0.614 & 0.026 & 0.013 \\
\hline \multirow[t]{2}{*}{$\mathrm{CS} / \mathrm{CT}$} & $0.458 / 0.762$ & $0.320 / 0.420$ & $0.910 / 0.924$ & $0.922 / 0.946$ \\
\hline & \multicolumn{4}{|c|}{ CT3 (Fullerene $\rightarrow$ Porphyrin) } \\
\hline$E_{x}, e V$ & 3.623 & 3.691 & 3.365 & 3.334 \\
\hline Transition (W) & $\begin{array}{c}\mathrm{H}-3-\mathrm{L}+4 \\
(0.27)\end{array}$ & $H-3-L+3(0.27)$ & $H-L(0.54)$ & $H-13-L+6(0.11)$ \\
\hline$f$ & 0.019 & 0.044 & 0.195 & 0.031 \\
\hline $\mathrm{CS} / \mathrm{CT}$ & $0.764 / 0.816$ & $0.755 / 0.803$ & $0.823 / 0.849$ & $0.479 / 0.541$ \\
\hline \multirow[t]{2}{*}{ Pertinent fragments } & F3 $\rightarrow$ F1 & $\mathrm{F} 2 \rightarrow \mathrm{F} 1$ & $\mathrm{~F} 2 / \mathrm{F} 3 \rightarrow \mathrm{F} 1$ & $\mathrm{~F} 2 \rightarrow \mathrm{F} 1$ \\
\hline & \multicolumn{4}{|c|}{ CT4 (Fullerene $\rightarrow$ Fullerene) } \\
\hline$E_{x}, e V$ & \multirow{5}{*}{$\mathrm{n} / \mathrm{a}$} & \multirow{5}{*}{$\mathrm{n} / \mathrm{a}$} & 3.499 & 3.392 \\
\hline Transition (W) & & & $H-3-L+5(0.17)$ & $\mathrm{H}-3-\mathrm{L}+1(0.22)$ \\
\hline$f$ & & & $<0.001$ & 0.011 \\
\hline $\mathrm{CS} / \mathrm{CT}$ & & & 0.546 / 0.593 & $0.568 / 0.721$ \\
\hline Pertinent fragments & & & $\mathrm{F} 3 \rightarrow \mathrm{F} 2$ & $\mathrm{~F} 3 \rightarrow \mathrm{F} 2$ \\
\hline
\end{tabular}

\section{Difference in the photoinduced ET properties of transoid and cisoid isomers.}

To address this issue, we analyzed related one-electron states and found that there are significant changes in the orbital energies associated with porphyrin and fullerene by passing from $S_{a} S_{p}$ to $S_{a} R_{a}$. Namely, the energy of both HOMO and LUMO orbitals of porphyrin decreases, while the energy of HOMO and LUMO of fullerene goes up. Thus in $\mathrm{S}_{\mathrm{a}} \mathrm{R}_{\mathrm{a}}$, porphyrin becomes stronger electron acceptor and fullerene becomes stronger electron donor as compared to $S_{a} S_{p}$ (Figure 3). 


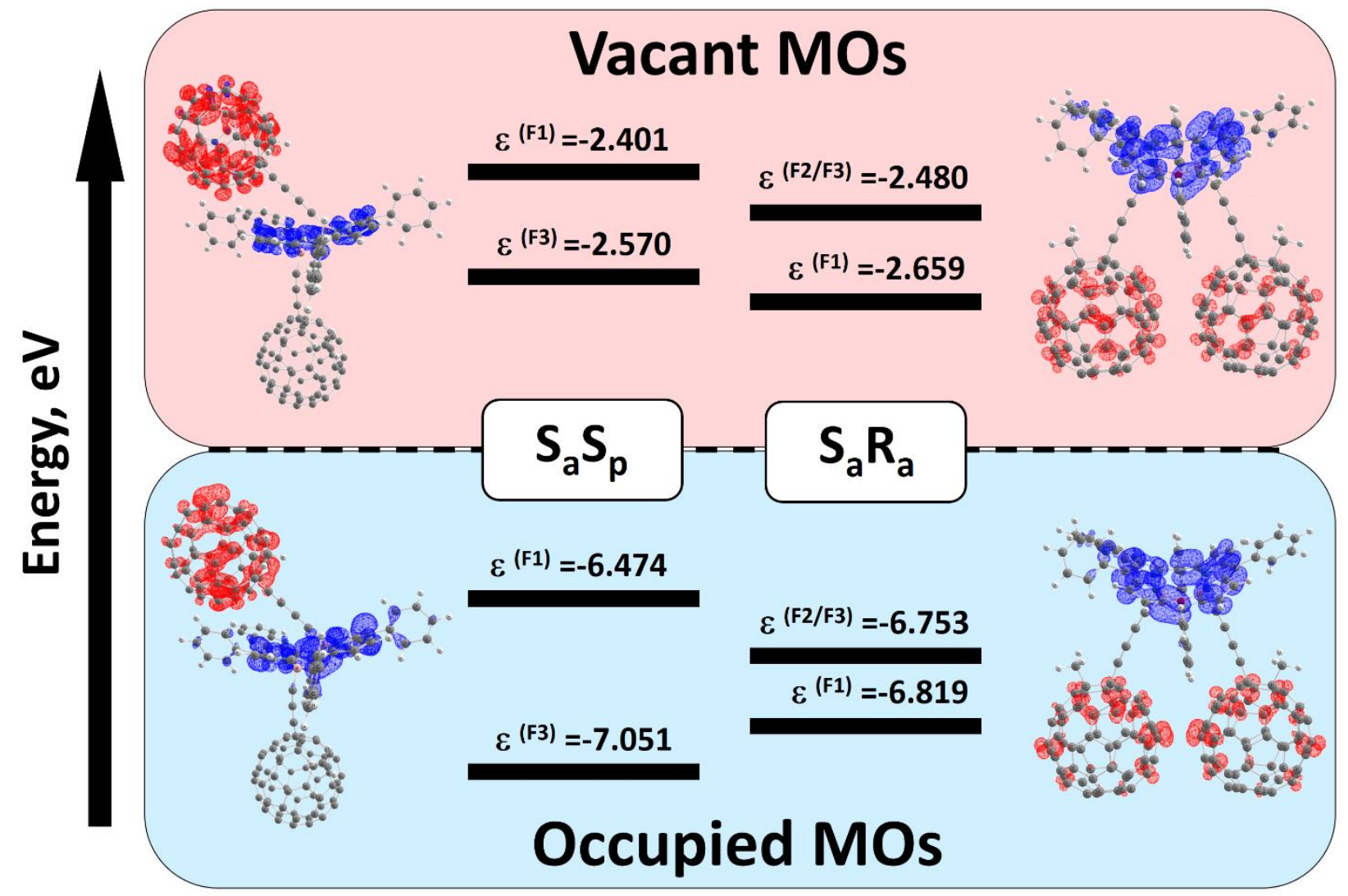

Figure 3. Relevant occupied and vacant molecular orbitals of porphyrin (fragment $F 1$ in blue) and fullerene (fragments $F 2 / F 3$ in red) in the $S_{a} S_{p}$ and $S_{a} R_{a}$ akamptisomers.

One of the most significant differences between $S_{a} S_{p}$ and $S_{a} R_{a}$ is the lack of the direct fullerene $\cdots$ fullerene interaction. To better understand its effect on $\mathrm{HOMO}$ and LUMO, several additional calculations were performed for isolated fullerene + linker fragments, $(F 2+F 5)$ and $(F 3+F 6)$ and the dyad $(F 2+F 5+F 3+F 6)$ at the original $S_{a} S_{p}$ and $S_{a} R_{a}$ geometries. The orbital energies of fullerene + linker fragments from $S_{a} S_{p}$ are almost insensitive to the presence of another fragment. By contrast, the significant interaction between (F2+F5) and $(F 3+F 6)$ in $S_{a} R_{a}$, modulates the LUMO energy by $0.18 \mathrm{eV}$ whereas the energy of HOMO remains almost unchanged (within 0.03 $\mathrm{eV}$ ) for both isomers. More details are given in SI (see Figure S3 and Table S3). The changes in the orbital energies of porphyrin are determined by several factors. On the one hand, significant alterations in the geometry of porphyrin are found when moving from $S_{a} S_{p}$ to $S_{a} R_{a}$. In order to describe the distortion effects, we considered two planes, one plane is formed by quinoxaline, another passes through the opposite side of porphyrin (see Figures S3). The angle between these planes in $\mathrm{S}_{\mathrm{a}} \mathrm{S}_{\mathrm{p}}$ is about $155^{\circ}$, whereas it is noticeably smaller, $131^{\circ}$, in $\mathrm{S}_{\mathrm{a}} \mathrm{R}_{\mathrm{a}}$. On the other hand, in both isomers, there is significant interaction between fullerenes and porphyrin. Note that fullerene being a strong acceptor retracts electron density from porphyrin, increasing the positive charge on the $F 1$ fragment. The charges on porphyrin in $S_{a} S_{p}$ and $S_{a} R_{a}$ are found to be 0.39 and 0.49 e. The effect of structural distortion was estimated using small models without the fullerene and linker fragments: LUMO of porphyrin in $\mathrm{S}_{a} R_{a}$ lies by $0.15 \mathrm{eV}$ lower in energy than the LUMO in $\mathrm{S}_{a} \mathrm{~S}_{\mathrm{p}}$. The fullerene-porphyrin interaction leads to a further decrease of the porphyrin LUMO energy (in the fullerene containing complexes the difference is $0.26 \mathrm{eV}$, see Figure S4). A similar analysis for the $S_{p} S_{a}$ and $S_{p} R_{p}$ pair cannot be carried out because the $S_{p} R_{p}$ isomer without fullerene substituents does not correspond to a minimum on the PES.

Thus, we can conclude that the anomalous behavior of porphyrin and fullerene in $S_{a} R_{p}$ and $S_{a} R_{a}$, where they act as electron donor and acceptor, respectively, is a consequence of several simultaneously acting factors: (i) the strong fullerene-fullerene interaction in cisoid isomers increases the HOMO energies of the fullerene fragment 
and thus reduces their acceptor properties; (ii) pronounced geometrical distortion and a larger positive charge on the porphyrin fragment decreases the LUMO energy in the cisoid structures and thus converting porphyrin into a better electron acceptor as compared to the transoid isomers.

\section{Environment effects on generation of CT states.}

It is well known that solvation may significantly influence both ground and excited states. Usually, the effect of solvation is relatively weak for LE states, while CT states can be strongly stabilized by the solvent. To assess the solvent effects on the excited states, the equilibrium solvation model with dichloromethane (DCM) as a solvent was applied. The polarity of the transoid and cisoid isomers differs significantly. The dipole moments of $\mathrm{S}_{\mathrm{a}} \mathrm{S}_{\mathrm{p}}$ and $\mathrm{S}_{\mathrm{p}} \mathrm{S}_{\mathrm{a}}$ are calculated to be 5.82 and $6.77 \mathrm{D}$, whereas it amounts to 13.19 and $10.69 \mathrm{D}$ for $\mathrm{S}_{\mathrm{a}} \mathrm{R}_{\mathrm{a}}$ and $\mathrm{S}_{\mathrm{p}} \mathrm{R}_{\mathrm{p}}$. Despite such notable difference in dipole moments for cisoid and transoid akamptisomers, due to the difference in spatial structure, the isomers, except $S_{p} R_{p}$, demonstrate quite similar ground state solvation energies (from - 0.57 to $0.62 \mathrm{eV}$, Table S4). Solvation energy for $S_{p} R_{p}$ isomer is $-0.46 \mathrm{eV}$. This fact can be explained by the significant structural difference of the $S_{p} R_{p}$ isomer. One of its fullerene substituents is located very close to the porphyrin. This arrangement significantly reduces the access of the solvent to both fragments, which in turn leads to a decrease in the solvation energy.

For the considered LE states of both types, the overall picture is very similar to the ground state. Comparison between excitation energies computed in the gas phase and in solution indicates that LE transition energies remain almost unchanged, which in turn perfectly correlates with the transition dipole moment changes $(\Delta \mu=$ vector difference between dipole moment of the state of interest and GS dipole moment). $\Delta \mu^{\mathrm{LE} 1}$ is less than 1.5D, while $\Delta \mu^{\text {LE2 }}$ does not exceed 2.7D, regardless the isomer. Detailed data for all akamptisomers are collected in Table S4, SI. Changes in the dipole moments associated with CT excited states are significantly larger compared to the LE states. For transoid isomers, $\Delta \mu^{\mathrm{CT1}}$ for lowest CT states (transitions associated with ET from porphyrin to fullerene moiety) is about $53 \mathrm{D}$ and $46 \mathrm{D}$ for $S_{a} S_{p}$ and $S_{p} S_{a}$ complexes, respectively. At the same time, for $S_{a} R_{a}$ cisoid complex, dipole moment change for CT state of a similar nature is comparable $\left(\Delta \mu^{\text {CT1 }}=51 \mathrm{D}\right)$. $\mathrm{S}_{\mathrm{p}} \mathrm{R}_{\mathrm{p}}$ isomer demonstrates significantly smaller value of transition dipole moment - only 31D. Such differences can easily be explained on the basis of the charge separation values. For $S_{p} R_{p}$ isomers, $C S$ is about $0.66 e$, whereas for $S_{a} R_{a}$ and transoid complexes this value is 1.5 times bigger (from 0.95 to $0.99 \mathrm{e}$, depending on isomer). Figure 4 shows the GS, LE and CT energies for the lowest lying singlet excited states in the gas phase and COSMO (DCM) solvent. 


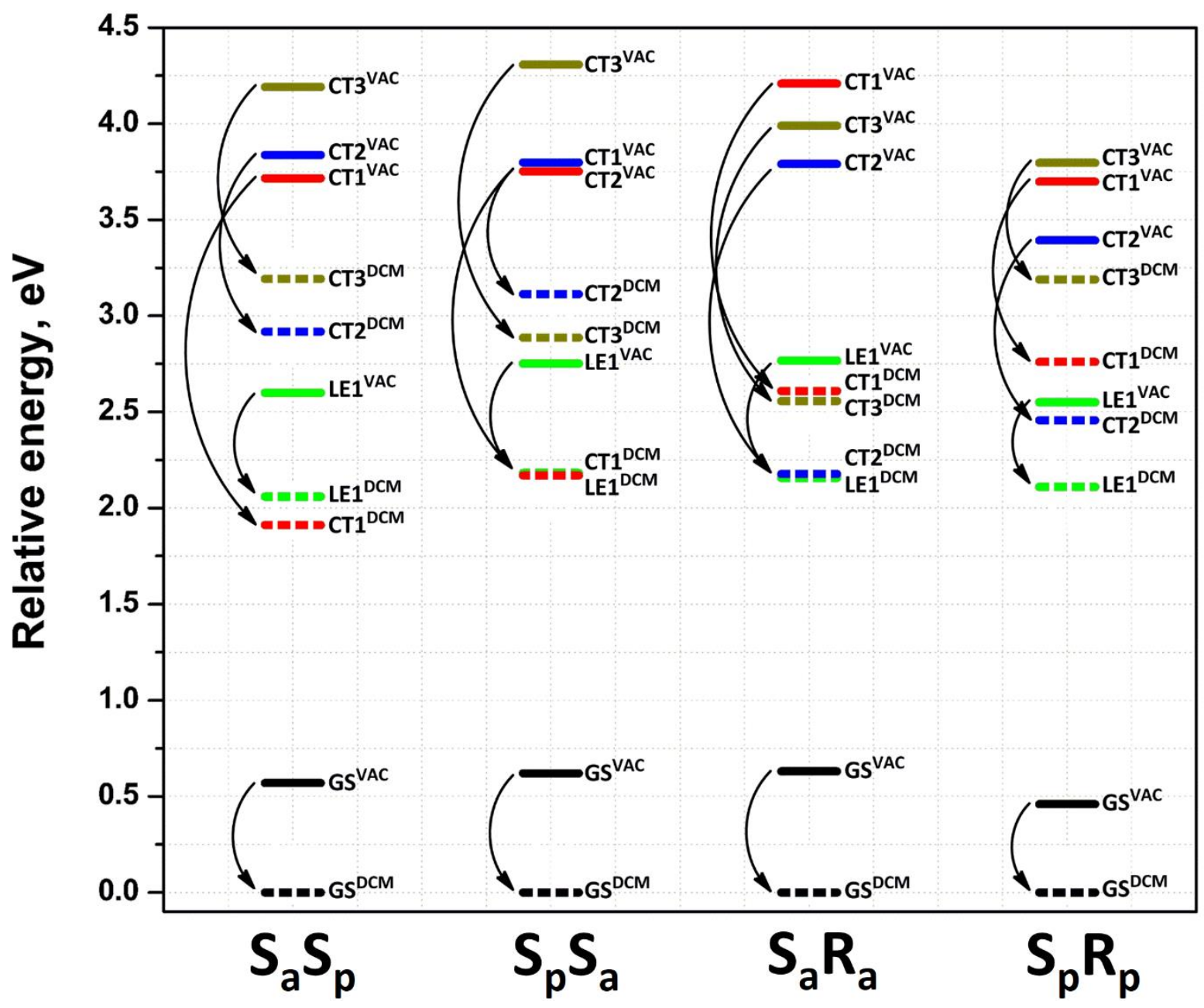

Figure 4. Relative energies of the ground state (GS), the first LE state (LE1) and the CT states (CT1, CT2, and CT3) for the $S_{a} S_{p}, S_{p} S_{a}, S_{a} R_{a}$ and $S_{p} R_{p}$ complexes computed in a gas-phase (VAC) and dichloromethane (DCM). CT1 is formed by Porphyrin $\rightarrow$ Fullerene ET, CT2 is formed by Linker $\rightarrow$ Porphyrin ET, whereas CT3 corresponds to Fullerene $\rightarrow$ Porphyrin ET.

Second lowest charge transfer state of transoid isomers corresponds to the ET from linker to porphyrin fragment and is characterized by considerably smaller value of CS (Table 1 ). However, for $S_{a} R_{a}$ and $S_{p} R_{p}$ isomers, a transition of this type is the lowest-lying and associated with CS of almost 1e. It should be noted that such electron transfer leads to the formation of a radical anion localized on the porphyrin. Previously, the formation of zinc tetraphenylporphyrin (ZnTPP) radical anion was reported for $\mathrm{Ce}_{2} @ / h-\mathrm{C}_{80}-$ ZnTPP complex by Guldi and coauthors.$^{46}$ The transient absorption spectra measured in polar media predict the formation of metastable (Ce@l $h$ $\left.\mathrm{C}_{80}\right)^{\circ+}-(\mathrm{ZnTPP})^{\cdot-}$ as a result of an oxidative charge transfer. In our case, the formed radical ion porphyrin complex is markedly stabilized by the solvent and the corresponding CT state becomes the lowest one in DCM solution.

\section{Electron transfer rates.}

Absorption of the light by the complex leads to the generation of the excited state, which extremely fast interconverts to lowest lying excited state. Due to low oscillator strength of lowest CT states of the studied complexes, the probability of their direct populations is also very low. The generation of CT1 for $S_{a} S_{p}$ and $S_{p} S_{a}$ and $C T 2$ in the $\mathrm{S}_{\mathrm{a}} \mathrm{R}_{\mathrm{a}}$ (CT states that in DCM solution have lower or similar energies than the LE1 state) are possible through charge separation of LE1 state. The rate of electron transfer is controlled by three parameters - the electronic coupling $V_{i j}$ between the initial LE and final CT states; the reorganization energy $\lambda$, and the Gibbs energy of the reaction $\Delta \mathrm{G}_{0}$. Below we estimated the rates for these processes in the nonadiabatic regime for transoid 
$S_{a} S_{p}$ and $S_{p} S_{a}$, and cisoid $S_{a} R_{a}$ isomers. ET rate was not calculated for $S_{p} R_{p}$ isomer due to the fact that denoted process is thermodynamically unfavorable $\left(\Delta \mathrm{G}_{0}=0.35 \mathrm{eV}\right)$.

The rate of the nonadiabatic $\mathrm{ET}, k_{\mathrm{ET}}$, can be expressed in terms of the electronic coupling squared, $V^{2}$, and the Franck-Condon Weighted Density of states (FCWD):

$$
k_{E T}=\frac{2 \pi}{\hbar^{2}} V^{2}(F C W D)
$$

that accounts for the overlap of vibrational states of donor and acceptor and can be approximately estimated using the classical Marcus equation: ${ }^{47}$

$$
(F C W D)=(4 \pi \lambda k T)^{-1 / 2} \exp \left[-\left(\Delta G^{0}+\lambda\right)^{2} / 4 \lambda k T\right]
$$

where $\lambda$ is the reorganization energy and $\Delta G^{0}$ is the standard Gibbs energy change of the process. The fragment charge difference $(F C D)^{48,49}$ method was employed to calculate the electronic couplings in this work.

The reorganization energy is usually divided into two parts, $\lambda=\lambda_{i}+\lambda_{s}$, including the internal and solvent terms. The internal reorganization energy $\lambda_{i}$ for Porphyrin $\rightarrow$ Fullerene ET corresponds to the energy of structural change when denoted fragments going from neutral-state geometries to charged-state geometries - anion and cation radicals for fullerene and porphyrin units respectively. The $\lambda_{i}$ for Linker $\rightarrow$ Porphyrin CT was calculated in the same manner. Solvent reorganization energy corresponds to the energy necessary to move solvent molecules from the position they occupy in the GS to the location they have in the CT state but without charge transfer having occurred. The $\lambda_{s}$ for particular CT states were computed as a difference between equilibrium and nonequilibrium solvation energies. Using the computed data listed in Table 2, we estimated the ET rates for two photoinduced charge separation reactions and the corresponding charge recombination processes.

Table 2. Electron transfer parameters and ET rates for charge separation (CS) reactions in DCM solvent.

\begin{tabular}{|c|c|c|c|c|c|}
\hline Isomer & Type & $\Delta \mathrm{G}_{0}{ }^{\mathrm{a}}, \mathrm{eV}$ & $|\mathrm{V}|$ & $\begin{array}{c}\text { Reorganization } \\
\text { energy } \lambda, \mathrm{eV}\end{array}$ & $\begin{array}{c}\text { Rate constant, } \\
\text { sec }^{-1}\end{array}$ \\
\hline $\mathrm{S}_{\mathrm{a}} \mathrm{S}_{\mathrm{p}}$ & $\mathrm{LE} 1 \rightarrow \mathrm{CT} 1$ & -0.148 & 0.0051 & 0.857 & $1.54 \cdot 10^{9}$ \\
\hline $\mathrm{S}_{\mathrm{p}} \mathrm{S}_{\mathrm{a}}$ & $\mathrm{LE} 1 \rightarrow \mathrm{CT} 1$ & 0.015 & 0.0127 & 0.744 & $1.68 \cdot 10^{9}$ \\
\hline $\mathrm{S}_{\mathrm{a}} \mathrm{R}_{\mathrm{a}}$ & $\mathrm{LE} 1 \rightarrow \mathrm{CT} 2$ & 0.015 & 0.0085 & 0.620 & $2.74 \cdot 10^{9}$ \\
\hline
\end{tabular}

${ }^{a}$ The Gibbs energy difference between the final and initial states in DCM solvent.

Thus our calculations predict that photoinduced charge separation occurs on the sub-nanosecond scale (1-10 ns $\left.\mathrm{s}^{-1}\right)$ and can significantly be modulated by selecting a proper akamptisomer.

\section{Conclusions}

The structure and excited state properties of quinoxalinoporphyrin-[60]fullerene akamptisomers have been studied by means of DFT calculations. Unlike difluoro derivatives of quinoxalinoporphyrin, stable structures have been found for all possible isomers of the fullerene containing complexes. To understand the effect of akamptisomerism on the photoinduced ET processes a detailed analysis of initial and final states involved in the ET is performed. Charge-transfer states of different character have been identified. It has been shown that depending on the isomer, the porphyrin unit in the dyad can act as either electron donor or electron acceptor. The computed ET rates allows one to predict how the efficiency of photoinduced charge separation depends on stereoisomeric diversity of the complex. The solvent effects have been found to be crucial for an efficient population of charge separated states. 


\section{Methods}

General. The geometry optimization for all akamptisomers was performed employing the DFT BLYP50,51 exchange-correlation functional using the resolution of identity approximation ( $\mathrm{RI}$, alternatively termed density fitting) ${ }^{52,53}$ implemented in the TURBOMOLE 7.0 program. ${ }^{54}$ Vertical excitation energies were calculated using TDA formalism ${ }^{55}$ with the range-separated functional from Handy and coworkers' CAM-B3LYP ${ }^{56}$ using Gaussian 16 (rev. A03) $)^{57}$ and Ahlrichs' def2-SVP basis set. ${ }^{58,59}$ The empirical dispersion D3 correction with Becke-Johnson damping, ${ }^{60,61}$ was employed. All resulted structures were visualized with Chemcraft $1.8{ }^{62}$ Topological analyses of the electron distributions were conducted according to the "Quantum Theory of Atoms in Molecules" (QTAIM) proposed by Bader. ${ }^{45,63}$ The QTAIM calculations were performed using the AIMALL suite of programs ${ }^{64}$ to evaluate bond and ring critical point properties and the associated bond descriptors.

Analysis of excited states. The quantitative analysis of exciton delocalization and charge transfer in the donor-acceptor complexes was carried out using a tool suggested recently by Plasser et al. ${ }^{65,66} \mathrm{~A}$ key quantity is the parameter $\Omega$ :

$$
\begin{aligned}
& \Omega(\mathrm{A}, \mathrm{B})=\frac{1}{2} \sum_{\alpha \in \mathrm{A}, \beta \in \mathrm{B}}\left[\left(\mathrm{SP}^{0 \mathrm{i}}\right)_{\alpha \beta}\left(\mathrm{P}^{0 \mathrm{i}} \mathrm{S}\right)_{\alpha \beta}+\mathrm{P}_{\alpha \beta}^{0 \mathrm{i}}\left(\mathrm{SP}^{0 \mathrm{i}} \mathrm{S}\right)_{\alpha \beta}\right] \\
& \chi\left(\mathrm{F}_{\mathrm{i}}\right)=\sum_{\mathrm{A} \in \mathrm{F}_{\mathrm{i}}} \Omega(\mathrm{A}, \mathrm{A}) \\
& \mathrm{CT}^{\mathrm{F}_{\mathrm{i}} \rightarrow \mathrm{F}_{\mathrm{j}}}=\sum_{\mathrm{A} \in \mathrm{F}_{\mathrm{i}}, \mathrm{B} \in \mathrm{F}_{\mathrm{j}}} \Omega(\mathrm{A}, \mathrm{B})+\Omega(\mathrm{B}, \mathrm{A}) \\
& \mathrm{CS}^{\mathrm{F}_{\mathrm{i}} \rightarrow \mathrm{F}_{\mathrm{j}}}=\sum_{\mathrm{A} \in \mathrm{F}_{\mathrm{i}}, \mathrm{B} \in \mathrm{F}_{\mathrm{j}}} \Omega(\mathrm{A}, \mathrm{B})-\Omega(\mathrm{B}, \mathrm{A})
\end{aligned}
$$

where $A$ and $B$ are atoms, $F_{i}$ and $F_{j}$ are fragments, $P^{0 i}$ is the transition density matrix for the $\psi_{0} \rightarrow \psi_{i}$ excitation, and $\mathrm{S}$ is the overlap matrix. $\chi\left(\mathrm{F}_{\mathrm{i}}\right)$ is the extent of exciton localization on the site $\mathrm{F}_{\mathrm{i}} . C T^{F_{i} \rightarrow F_{j}}$ is the weight of CT configuration in the excited state $\psi_{\mathrm{i}}$. CT means the total amount of the electron density transferred between fragments. CS is a measure of the charge separation between fragments $F_{i}$ and $F_{j}$ due to the transition. Note that in the situation when charge transfer $\left(F_{i} \rightarrow F_{j}\right)$ is equal to the back transfer $\left(F_{j} \rightarrow F_{i}\right)$ there is no charge separation between the fragments, $\mathrm{CS}^{\mathrm{F}_{\mathrm{i}} \rightarrow \mathrm{F}_{\mathrm{j}}}$ is equal to zero.

Solvent Effects. The equilibrium solvation energy $E_{s}^{e q}$ in a medium with dielectric constant $\varepsilon$ was estimated using a COSMO-like polarizable continuum model (CPCM) in the monopole approximation. ${ }^{67}$

$$
-\mathrm{E}_{\mathrm{S}}^{\mathrm{eq}}(\mathrm{Q}, \varepsilon)=-\frac{1}{2} f(\varepsilon) \mathrm{Q}^{+} \mathrm{DQ}
$$

where $f(\varepsilon)$ is the dielectric scaling factor, $f(\varepsilon)=\frac{\varepsilon-1}{\varepsilon}, \mathbf{Q}$ is the vector of $n$ atomic charges in the molecular system, and $\mathbf{D}$ is the $n \times n$ symmetric matrix determined by the shape of the boundary surface between solute and solvent; $\mathbf{D}=\mathbf{B}^{+} \mathbf{A}^{-1} \mathbf{B}$, where the $m \times m$ matrix $\mathbf{A}$ describes electrostatic interaction between $m$ surface charges and the $m \times n \mathbf{B}$ matrix describes the interaction of the surface charges with $n$ atomic charges of the solute. Atomic charges in the excited state $\psi_{i}$ were calculated using Eq. (1).

\section{Acknowledgments}

We are grateful for financial support from the Spanish MINECO (Network CTQ2016-81911-REDT, projects CTQ2017-85341-P and CTQ2015-69363-P, and Juan de la Cierva formación contract FJCl-2016-29448 to A.J.S.), 
the Catalan DIUE (2017SGR39, XRQTC, and ICREA Academia 2014 Award to M.S.), and the FEDER fund (UNGI10$4 \mathrm{E}-801)$.

\section{References}

[1] R. L. House, N. Y. M. Iha, R. L. Coppo, L. Alibabaei, B. D. Sherman, P. Kang, M. K. Brennaman, P. G. Hoertz, T. J. Meyer J. Photochem. Photobiol. C 2015, 25, 32-45.

[2] K. P. Sokol, W. E. Robinson, J. Warnan, N. Kornienko, M. M. Nowaczyk, A. Ruff, J. Z. Zhang, E. Reisner Nat. Energy 2018. doi:10.1038/s41560-018-0232-y

[3] M. R. Wasielewski, Chem. Rev. 1992, 92, 435-461.

[4] G. Bottari, O. Trukhina, M. Ince, T. Torres, Coord. Chem. Rev. 2012, 256, 2453-2477.

[5] F. D'Souza, O. Ito, Coord. Chem. Rev. 2005, 249, 1410-1422.

[6] M. Tanaka, K. Ohkubo, C. P. Gros, R. Guilard, S. Fukuzumi, J. Am. Chem. Soc. 2006, 128, 14625-14633.

[7] K. Kalyanasundaram, M. Graetzel, Curr. Opin. Biotechnol. 2010, 21, 298-310.

[8] E. S. Andreiadis, M. Chavarot-Kerlidou, M. Fontecave, V. Artero, Photochem. Photobiol. 2011, 87, 946964.

[9] H. S. Lee, J. H. Han, J. H. Park, M. E. Heo, K. Hirakawa, S. K. Kim, D. W. Cho, Phys. Chem. Chem. Phys. 2017, 19, 27123-27131.

[10] D. M. Guldi, Chem. Soc. Rev. 2002, 31, 22-36.

[11] M.S Choi, T. Aida, H. Luo, Y. Araki, O. Ito, Angew. Chem., Int. Ed. 2003, 42, 4060-4063.

[12] S. Fukuzumi, K. Ohkubo, T. Suenobu, Acc. Chem. Res. 2014, 47, 1455-1464.

[13] F. D'Souza, O. Ito, Chem. Soc. Rev. 2012, 41, 86-96.

[14] S. Shanmugam, J. T. Xu, C. Boyer, Angew. Chem., Int. Ed. 2016, 55, 1036-1040.

[15] F. D'Souza, R. Chitta, K. Ohkubo, M. Tasior, N. K. Subbaiyan, M. E. Zandler, M. K. Rogacki, D. T. Gryko, S. Fukuzumi, J. Am. Chem. Soc. 2008, 130, 14263-14272.

[16] M. E. El-Khouly, O. Ito, P. M. Smith, F. D'Souza, J. Photochem. Photobiol., C 2004, 5, 79-104.

[17] S. Campidelli, C. Sooambar, E. Lozano Diz, C. Ehli, D. M. Guldi, M. Prato, J. Am. Chem. Soc. 2006, 128, 12544-12552.

[18] T. Nakamura, M. Fujitsuka, Y. Araki, O. Ito, J. Ikemoto, K. Takimiya, Y. Aso, T. Otsubo, J. Phys. Chem. B 2004, 108, 10700-10710.

[19] Z. D. Liu, H. X. Zhao, C. Z. Huang, PLoS One 2012, 7, e50367.

[20] S. Shanmugam, J. Xu, C. Boyer, J. Am. Chem. Soc. 2015, 137, 9174-9185.

[21] D. M. Guldi, M. Prato, Acc. Chem. Res. 2000, 33, 695-703.

[22] M. Prato, J. Mater. Chem. 1997, 7, 1097-1109.

[23] M. Ortiz, S. Cho, J. Niklas, S. Kim, O. G. Poluektov, W. Zhang, G. Rumbles, J. Park, J. Am. Chem. Soc. 2017, 139, 4286-4289.

[24] M. C. Scharber, D. Wuhlbacher, M. Koppe, P. Denk, C. Waldauf, A. J. Heeger, C. L. Brabec, Adv. Mater. 2006, 18, 789-794.

[25] B. C. Thompson, J. M. J. Frechet, Angew. Chem., Int. Ed. 2008, 47, 58-77.

[26] H. Imahori, K. Hagiwara, T. Akiyama, M. Aoki, S. Taniguchi, T. Okada, M. Shirakawa, Y. Sakata, Chem. Phys. Lett. 1996, 263, 545-550.

[27] J. L. Segura, N. Martín, D. M. Guldi, Chem. Soc. Rev. 2005, 34, 31-47.

[28] J. L. Delgado, P.A. Bouit, F. Salvatore, M.A. Herranz, N. Martin, Chem. Commun. 2010, 40, 4853-4856.

[29] R. W. Wagner, T. E. Johnson, J. S. Lindsey, J. Am. Chem. Soc. 1996, 118, 11166-11180.

[30] A. Kongkanand, K. Tvrdy, K. Takechi, M. Kuno, P. V. Kamat, J. Am. Chem. Soc. 2008, 130, 4007-4015.

[31] D. T. Gryko, C. Clausen, K. M. Roth, N. Dontha, D. F. Bocian, W. G. Kuhr, J. S. Lindsey, J. Org. Chem. 2000, 65, 7345-7355.

[32] S. I. Yang, J. Seth, T. Balasubramanian, D. Kim, J. S. Lindsey, D. Holten, D. F. Bocian, J. Am. Chem. Soc. 1999, $121,4008-4018$.

[33] D. Holten, D. F. Bocian, J. S. Lindsey, Acc. Chem. Res. 2002, 35, 57-69.

[34] S. A. Vail, D. I. Schuster, D. M. Guldi, M. Isosomppi, N. Tkachenko, H. Lemmetyinen, A. Palkar, L. Echegoyen, X. H. Chen, J. Z. H. Zhang, J. Phys. Chem. B 2006, 110, 14155-14166. 
[35] W. J. Belcher, P. D. W. Boyd, P. J. Brothers, M. J. Liddell, C. E. F. Rickard, J. Am. Chem. Soc. 1994, 116, 8416-8417.

[36] P. J. Brothers, in Adv. Organomet. Chem. Vol. 48 (eds Robert West \& Anthony F. Hill) 289-342 (Academic Press, 2001).

[37] P. J. Brothers, J. Porphyr. Phthalocya. 2002, 06, 259-267.

[38] A. M. Albrett, P. D. W. Boyd, G. R. Clark, E. Gonzalez, A. Ghosh, P. J. Brothers, Dalton Trans. 2010, 39, 4032-4034.

[39] P. J. Canfield, I. M. Blake, Z.-L. Cai, I. J. Luck, E. Krausz, R. Kobayashi, J. R. Reimers, M. J. Crossley, Nat. Chem. 2018, 10, 615-624.

[40] A. J. Stasyuk, O. A. Stasyuk, S. Filippone, N. Martín, M. Solà, A. A. Voityuk, Chem. Eur. J. 2018, 24, 1302013025.

[41] P. Timmerman, H. L. Anderson, R. Faust, J. F. Nierengarten, T. Habicher, P. Seiler, F. Diederich, Tetrahedron 1996, 52, 4925-4947.

[42] S. A. Vail, J. P. C. Tome, P. J. Krawczuk, A. Douradin, V. Shafirovich, J. A. S. Cavaleiro, D. I. Schuster, J. Phys. Org. Chem. 2004, 17, 814-818.

[43] G. Ulrich, C. Goze, M. R. Guardigli, R. Ziessel, Angew. Chem. Int Ed. 2005, 44, 3694-3698.

[44] C. Goze, G. Ulrich, R. Ziessel, J. Org. Chem. 2007, 72, 313-322.

[45] R. F. W. Bader, Chem. Rev. 1991, 91, 893-928.

[46] L. Feng, S. G. Radhakrishnan, N. Mizorogi, Z. Slanina, H. Nikawa, T. Tsuchiya, T. Akasaka, S. Nagase N. Martín, D. M. Guldi, J. Am. Chem. Soc. 2011, 133, 7608-7618.

[47] R. A. Marcus, N. Sutin, Biochim. Biophys. Acta, Rev. Bioenerg. 1985, 811, 265-322.

[48] A. A. Voityuk, N. Rösch, J. Chem. Phys. 2002, 117, 5607-5616.

[49] A. A. Voityuk, Phys. Chem. Chem. Phys. 2012, 14, 13789-13793.

[50] A. D. Becke, Phys. Rev. A 1988, 38, 3098-3100.

[51] C. Lee, W. Yang, R. G. Parr, Phys. Rev. B 1988, 37, 785-789.

[52] K. Eichkorn, O. Treutler, H. Öhm, M. Häser, R. Ahlrichs, Chem. Phys. Lett. 1995, 240, 283-290.

[53] K. Eichkorn, F. Weigend, O. Treutler, R. Ahlrichs, Theor. Chem. Acc. 1997, 97, 119-124.

[54] TURBOMOLE 7.0 2015, a development of the University of Karlsruhe and Forschungszentrum Karlsruhe GmbH 1989-2007, TURBOMOLE GmbH since 2007; available from http://www.turbomole.com.

[55] S. Hirata, M. Head-Gordon, Chem. Phys. Lett. 1999, 314, 291-299.

[56] T. Yanai, D. P. Tew, N. C. Handy, Chem. Phys. Lett. 2004, 393, 51-57.

[57] Gaussian 16, Revision A.03 (Wallingford CT, 2016). Full citation see in SI.

[58] F. Weigend, R. Ahlrichs, Phys. Chem. Chem. Phys. 2005, 7, 3297-3305.

[59] F. Weigend, Phys. Chem. Chem. Phys. 2006, 8, 1057-1065.

[60] S. Grimme, J. Antony, S. Ehrlich, H. Krieg, J. Chem. Phys. 2010, 132, 154104.

[61] S. Grimme, S. Ehrlich, L. Goerigk, J. Comput. Chem. 2011, 32, 1456-1465.

[62] G. A. Zhurko, Chemcraft 1.80 (build 523b) - graphical program for visualization of quantum chemistry computations. (https://chemcraftprog.com).

[63] "Atoms in Molecules: A Quantum Theory", R.F.W. Bader, Oxford University Press, Oxford (1990).

[64] AIMAll (Version 14.06.21), Todd A. Keith, TK Gristmill Software, Overland Park KS, USA, 2014 (aim.tkgristmill.com).

[65] F. Plasser, H. Lischka, J. Chem. Theory Comput. 2012, 8, 2777-2789.

[66] F. Plasser, S. A. Bäppler, M. Wormit, A. Dreuw, J. Chem. Phys. 2014, 141, 024107.

[67] J. Tomasi, B. Mennucci, R. Cammi, Chem. Rev. 2005, 105, 2999-3093. 


\section{TABLE OF CONTENTS GRAPHIC}

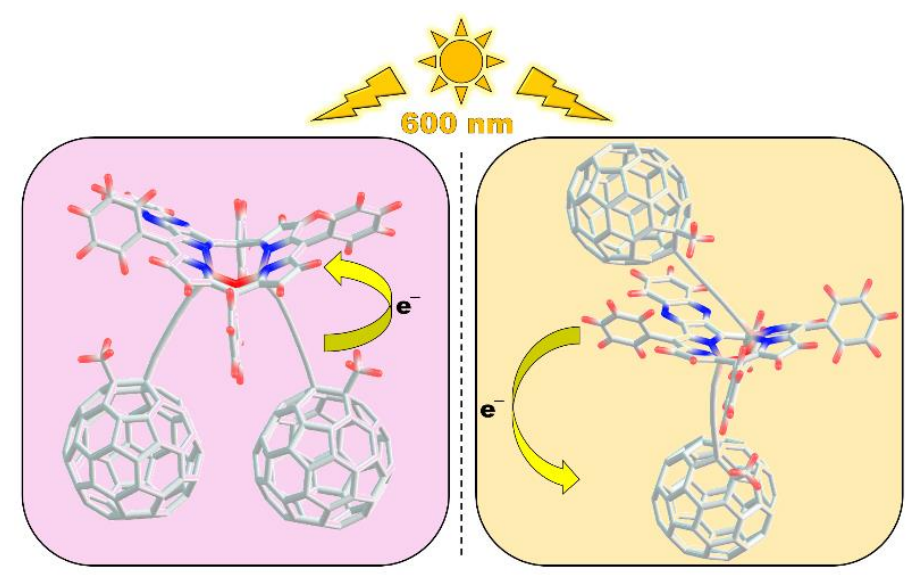

